\title{
Impact of Fuel Metal Impurities on the Durability of a Light-Duty Diesel Aftertreatment System
}

\author{
Aaron Williams, Jonathan Burton and Robert L. McCormick \\ National Renewable Energy Laboratory \\ Todd Toops, Andrew A. Wereszczak, Ethan E. Fox and Michael J. Lance \\ Oak Ridge National Laboratory
}

Giovanni Cavataio, Douglas Dobson and Jim Warner

Ford Motor Co

Rasto Brezny

Manufacturers of Emission Controls Assoc

K. Nguyen and D. William Brookshear

University of Tennessee - Knoxville

\begin{abstract}
Alkali and alkaline earth metal impurities found in diesel fuels are potential poisons for diesel exhaust catalysts. Using an accelerated aging procedure, a set of production exhaust systems from a 2011 Ford F250 equipped with a 6.7L diesel engine have been aged to an equivalent of 150,000 miles of thermal aging and metal exposure. These exhaust systems included a diesel oxidation catalyst (DOC), selective catalytic reduction (SCR) catalyst, and diesel particulate filter (DPF). Four separate exhaust systems were aged, each with a different fuel: ULSD containing no measureable metals, B20 containing sodium, B20 containing potassium and B20 containing calcium. Metals levels were selected to simulate the maximum allowable levels in B100 according to the ASTM D6751 standard. Analysis of the aged catalysts included Federal Test Procedure emissions testing with the systems installed on a Ford F250 pickup, bench flow reactor testing of catalyst cores, and electron probe microanalysis (EPMA). The thermo-mechanical properties of the aged DPFs were also measured.
\end{abstract}

EPMA imaging of aged catalyst parts found that both the $\mathrm{Na}$ and $\mathrm{K}$ penetrated into the washcoat of the DOC and SCR catalysts, while $\mathrm{Ca}$ remained on the surface of the washcoat.
Bench flow reactor experiments were used to measure the standard $\mathrm{NOx}$ conversion, $\mathrm{NH}_{3}$ storage and $\mathrm{NH}_{3}$ oxidation for each of the aged SCR catalysts. Flow reactor results showed that the first inch of the SCR catalysts exposed to $\mathrm{Na}$ and $\mathrm{K}$ had reduced NOx conversion through a range of temperatures and also had reduced $\mathrm{NH}_{3}$ storage capacity. The SCR catalyst exposed to Ca had similar NOx conversion and $\mathrm{NH}_{3}$ storage performance compared to the catalyst aged with ULSD. Using a chassis dynamometer, vehicle emissions tests were conducted with each of the aged catalyst systems installed onto a Ford F250 pickup. Regardless of the evidence of catalyst deactivation seen in flow reactor experiments and EPMA imaging, the vehicle successfully passed the $0.2 \mathrm{gram} /$ mile NOx emission standard with each of the four aged exhaust systems. This indicates that total catalyst volume is adequate to accommodate the catalyst activity loss observed in the flow reactor experiments.

\section{INTRODUCTION}

Biodiesel can be made from various renewable sources such as vegetable oil, animal fat, or waste cooking oil. It is produced through transesterification of the oil or fat with methanol, resulting in mono-alkyl esters and the co-product glycerin. The process occurs in the presence of a catalyst, 
typically sodium hydroxide or potassium hydroxide [1]. Following transesterification and separation of the glycerin, the biodiesel must be purified by extraction of the impurities into water or other means. In this process, residual amounts of sodium $(\mathrm{Na})$ or potassium $(\mathrm{K})$ from the catalyst can be left behind. In addition, small amounts of calcium $(\mathrm{Ca})$ or magnesium $(\mathrm{Mg})$ can be added to the fuel from the purification process $[\underline{2}, \underline{3}]$. $\mathrm{Na}$ and $\mathrm{Ca}$ may also be present in conventional diesel fuel and have been implicated in internal injector deposits $[\underline{4}, \underline{5}]$. Regardless of the source, these metallic fuel contaminants are converted to oxides, sulfates, hydroxides or carbonates in the combustion process to form an inorganic ash that can be deposited onto the exhaust emission control devices found in modern diesel engines. Alkali metals are well known poisons for catalysts and have been shown to negatively impact the mechanical properties of ceramic substrates [ㅁ,,$]$. Furthermore, alkali metal hydroxides such as $\mathrm{Na}$ and $\mathrm{K}$ are volatilized in the presence of steam and can, therefore, penetrate the catalyst washcoat or substrate. Early results showed no negative short-term impact of biodiesel on the performance of emission control system components $[\underline{8}, \underline{9}, \underline{10}, \underline{11}]$. Here, we examine long-term impacts with a focus on the effects of residual metals.

\section{Phase I Study}

In 2011, a study led by the National Renewable Energy Laboratory (NREL) investigated the impact of these alkali and alkaline earth metals on the durability of catalysts in a heavy-duty diesel application [12]. This study used an accelerated aging method to expose catalysts to the equivalent of 435,000 miles of fuel metal and thermal exposure. The aftertreatment system consisted of a diesel oxidation catalyst (DOC), diesel particulate filter (DPF), and a selective catalytic reduction ( $\mathrm{SCR}$ ) catalyst placed at the end. Several key findings in this study created the motivation for further research, which is the purpose of the work described in this paper. This previous study found that a cordierite DPF exposed to the equivalent of 435,000 miles through accelerated aging with $\mathrm{Na}, \mathrm{K}$ and $\mathrm{Ca}$ in the fuel experienced a $69 \%$ decrease in thermal shock resistance, relative to a system aged with no metals in the fuel. This study also found that the DOC exposed to the equivalent of 150,000 miles with fuel containing metals experienced a loss of catalytic activity for hydrocarbons (HC) and NO oxidation when compared with a catalyst aged with no metals. The study showed that an SCR catalyst aged to 435,000 miles with fuel containing metals showed a slight loss in NOx conversion when compared with one aged with no metals.

This first phase of work studied a typical heavy-duty configuration where the SCR catalyst is placed downstream of the DPF. However, a light-duty system typically places the SCR catalyst upstream of the DPF where it would experience more exposure to metals and high DPF regeneration temperatures. While the U.S. Environmental Protection Agency's "full useful life" requirement is much shorter for a light-duty application, the system configuration could potentially represent a worst-case scenario for durability. The purpose of the work presented in this paper is to investigate this possibility.

\section{TEST METHODS}

\section{Catalyst Aging}

The exhaust catalysts selected for accelerated aging studies were from a production 2011 Ford F250 pickup equipped with a $6.7 \mathrm{~L}$ diesel engine. These systems included a DOC, SCR, and a DPF. The DOC consisted of two bricks mounted in series with a total volume of $4.35 \mathrm{~L}$. The SCR system included a pair of $\mathrm{Cu} /$ zeolite bricks mounted in series with a total volume of $9.88 \mathrm{~L}$. The $\mathrm{DPF}$ was a catalyzed $\mathrm{SiC}$ substrate and had a total volume of 8.2 L. Further catalyst details are listed in Table 1. Four OEM exhaust systems were purchased from a local dealership to be used for accelerated aging. Each system was instrumented for temperature and pressure measurements and for exhaust sampling. These systems, as purchased from the dealership, were welded from end to end with no access to the individual catalyst bricks. Therefore, the DPF section was cut and flanged from the rest of the exhaust to allow for weighing of the DPF to quantify ash loading. A schematic of the exhaust system is shown in Figure 1.

Table 1. Catalyst Specification

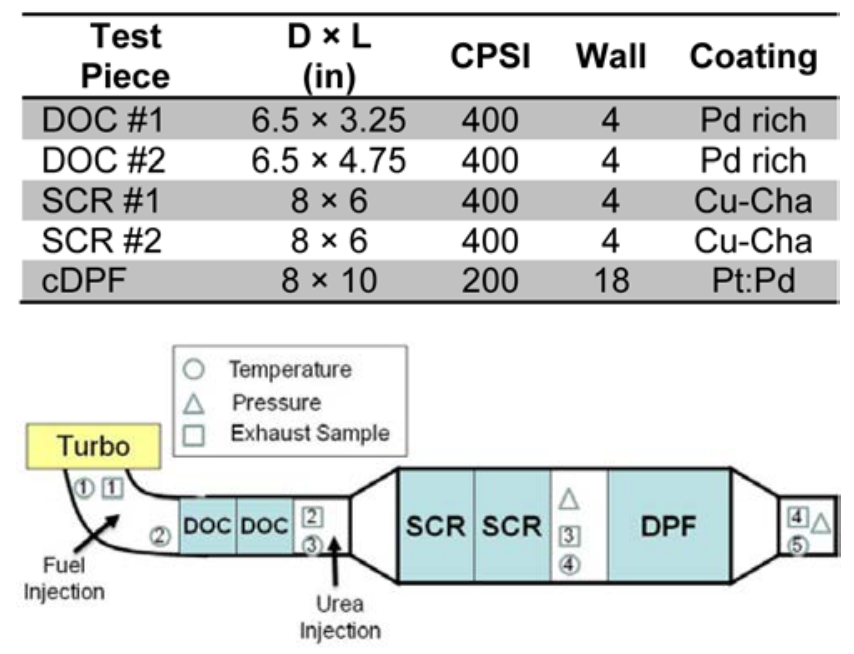

Figure 1. Schematic of exhaust system

For accelerated aging, these full exhaust systems were placed onto an accelerated aging platform that was described in the Phase 1 study [12]. The accelerated aging platform consisted of a Caterpillar 2008 C9 ACERT engine. This is an $8.8 \mathrm{~L}$, 300-hp engine calibrated to meet the Tier III off-road emissions limit. The engine is turbocharged and direct injected and does not use an exhaust catalyst in its base configuration. By retrofitting the engine with exhaust emission controls, it served as a platform for exposing various catalysts and filters to biodiesel exhaust gas. The 
exhaust was retrofitted with a fuel injector placed $10 \mathrm{~cm}$ downstream of the turbo flange and $183 \mathrm{~cm}$ upstream of a DOC. This fuel injector was used to simulate hot exhaust temperatures typical of a DPF regeneration event. A threemode test cycle was developed for the Caterpillar engine in order to achieve catalyst temperature and space velocity conditions consistent with operating parameters in an F250 pickup. The three modes, along with conditions for the SCR catalyst, are shown in Table 2. An illustration of a 10-hour segment of the test cycle is shown in Figure 2. Mode 1 represents typical low-temperature operation for this system and allows for some level of soot accumulation on the DPF. Mode 2 represents typical high-temperature operation without the use of active DPF regeneration. Mode 3 represents temperatures typical of an active DPF regeneration event. This three-mode cycle is one hour in length and is repeated 100 times. Operating this cycle for 100 hours results in approximately 50 hours of DPF regeneration conditions. Based on the estimations below, this is equivalent to 150,000 miles of thermal aging for the exhaust system.

\section{Thermal aging exposure estimate}

Peak temperatures of a DPF regeneration last 10 minutes and occurs every 500 miles

150,000 miles $/ 500$ miles $\times 10$ min $=50$ hours

$S C R$ inlet temperatures commonly reach $700^{\circ} \mathrm{C}$ in a DOC $+S C R+D P F$ configuration.

Table 2. Catalyst Aging Conditions

\begin{tabular}{lccc}
\hline \multicolumn{1}{c}{ Engine Mode } & $\begin{array}{c}\text { Time } \\
(\mathrm{min})\end{array}$ & $\begin{array}{c}\text { SCR SV } \\
(1 / \mathrm{hr})\end{array}$ & $\begin{array}{c}\text { SCR inlet T } \\
\left({ }^{\circ} \mathrm{C}\right)\end{array}$ \\
\hline 1 (low-temp operation) & 15 & $20 \mathrm{k}$ & 200 \\
2 (high-temp operation) & 15 & $57 \mathrm{k}$ & 340 \\
3 (regen operation) & 30 & $57 \mathrm{k}$ & 700 \\
\hline
\end{tabular}

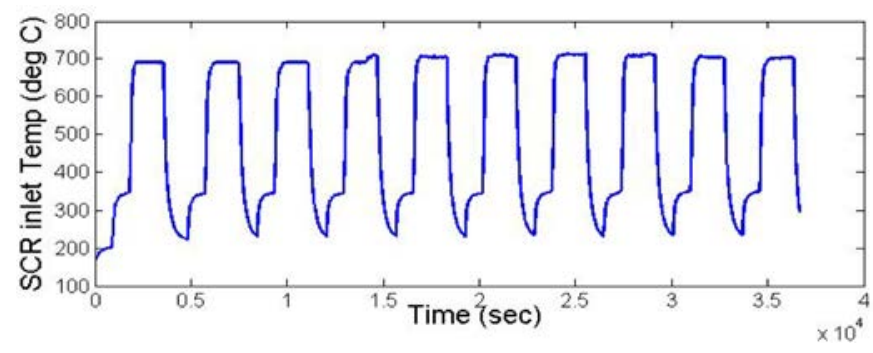

Figure 2. 10 hour example of the aging cycle

Using this accelerated aging platform, four identical exhaust systems were aged, each with a different fuel: petroleum diesel containing no detectable metals, B20 doped with $\mathrm{Na}$, B20 doped with $\mathrm{K}$, and B20 doped with $\mathrm{Ca}$. The petroleum diesel was an ultra low sulfur diesel (ULSD) and contained no measureable quantities of $\mathrm{Na}, \mathrm{K}$ or $\mathrm{Ca}$ at a detection limit of $1 \mathrm{ppm}$. Each of the biodiesel fuels was a blend of this same ULSD with $20 \mathrm{vol} \%$ soy-based biodiesel. The soy-based biodiesel also contained no measureable quantities of $\mathrm{Na}, \mathrm{K}$ or Ca. The B20 was blended in 250 gallon tote quantities and then doped with metal impurities to achieve precisely controlled levels. Laboratory experiments were conducted to determine compounds suitable for doping the B20 based on solubility at room temperatures. The dopants used to add $\mathrm{Na}$, $\mathrm{K}$ and $\mathrm{Ca}$ were dioxtyl sulfonate sodium salt, potassium dodecylbenzene and calcium napthenate, respectively. Once the B20 batch was blended, it was doped with the desired metal impurity and allowed to mix overnight with a paddle wheel agitator. A sample was then collected for analysis. Samples were collected from the top and bottom of the tote to ensure a homogeneous mixture of the dopant.

Fuel dopant levels were selected to achieve 150,000 miles worth of metal exposure in the 100 hour aging period. The dopants were added to the fuel at $14 \mathrm{ppm}$. This level was chosen to achieve 150,000 miles worth of metal exposure, assuming normal vehicle operation with a B20 blended from B100 at the ASTM International's specification limit of 5 ppm metals. This would correspond to a B20 fuel containing $1 \mathrm{ppm}$ of the impurity. The calculations and assumptions used for this estimate are shown below.

\section{Biodiesel metal exposure estimate}

Fuel economy of a Ford F-series pickup $=18 \mathrm{mpg}$

$0.00015 \%$ of B20 becomes oxide ash at current spec limits (Assuming 1ppm Na in B20 forming $\mathrm{Na2O}$ ash)

150,000 miles $/ 18 \mathrm{mpg} \times 0.00015 \% \times 3.1 \mathrm{~kg} / \mathrm{gal}=39 \mathrm{grams}$

Accelerated ash loading calculation

Test length $=100$ hours

Caterpillar engine fuel consumption over 3-mode test cycle $=$ $19.6 \mathrm{~kg} / \mathrm{hr}$

$0.0021 \%$ of B20 becomes ash $(14 \times$ metal in fuel $)$

$100 \mathrm{hrs} \times 19.6 \mathrm{~kg} / \mathrm{hr} \times 0.0021 \%=41 \mathrm{grams}$

\section{Emissions Testing of Aged Catalysts}

The 100 hours of accelerated aging was interrupted at 10hour intervals for DPF weighing and emissions testing. At the 10- hour interval, the exhaust system was removed from the accelerated aging test bed. The DPF was separated from the rest of the exhaust and weighed. Then the full exhaust system was installed onto the Ford F250 pickup truck for emissions testing. The vehicle was tested on a chassis dynamometer over the Federal Test Procedure (FTP) cycle with measurement of regulated emissions following U.S. EPA 
certification test methods [ $[\underline{13}]$. The purpose of intermittent emissions evaluation was to identify the onset of catalyst failure due to metal exposure. Prior to each emission test, the system was prepped to ensure that the catalysts were at the same state. The catalyst prep procedure consisted of (1) conducting a forced DPF regeneration event while driving the Highway Fuel Economy Test (HWFET) cycle, followed by (2) conducting two repeats of the LA4 test cycle, and finally, (3) a minimum 7-hour soak period. This system conditioning ensured that the vehicle did not initiate a DPF regeneration event during the FTP and that the SCR catalysts had the same opportunity for ammonia $\left(\mathrm{NH}_{3}\right)$ adsorption prior to the FTP emissions test.

Emissions concentrations were measured at multiple locations in the exhaust, as indicated in Figure 1, to allow for calculation of percent conversion. Dilute bag emissions were measured for all three phases of the FTP and a final calculation was made in grams/mile of $\mathrm{NOx}$, carbon monoxide $(\mathrm{CO})$, total $\mathrm{HC}$, and carbon dioxide $\left(\mathrm{CO}_{2}\right)$. All system prep work and emissions testing was conducted with a standard ULSD, regardless of the fuel type used to age the catalyst.

\section{Postmortem Analysis of Aged Catalysts}
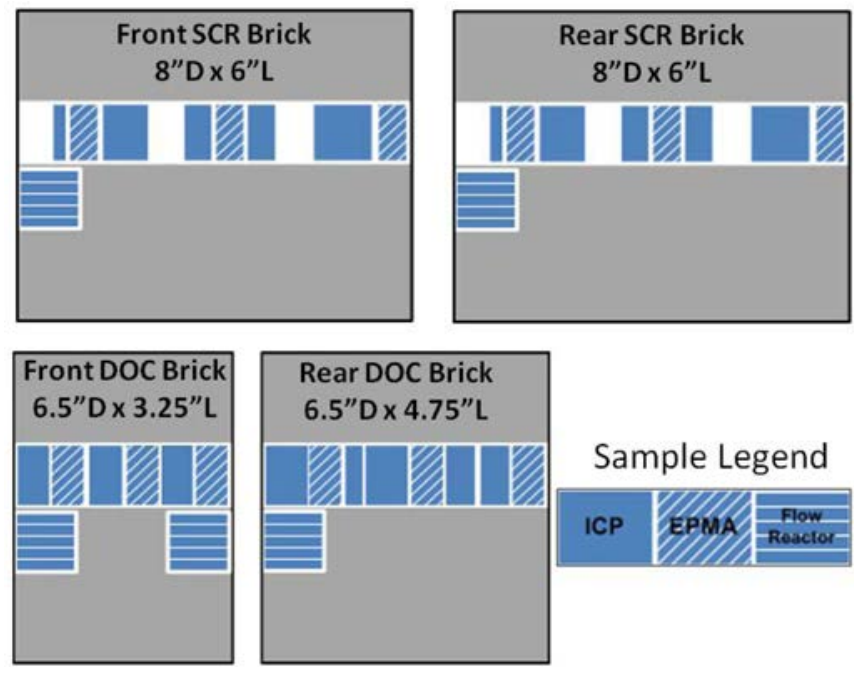

Figure 3. Sample location for postmortem analysis

Following the end of simulated aging and the final emissions tests on the F250 pickup truck, each of the four exhaust systems was sent to Oak Ridge National Laboratory (ORNL) and Ford for further postmortem analysis. In preparation for postmortem analysis core sections were harvested from each of the catalyst bricks. One inch diameter cores were taken down the length of each of the DOC and SCR bricks. These cores were taken close to the radial center of each brick. Electron probe microanalysis (EPMA) was used to determine the location and concentration of the metal species and ash. Bench flow reactor experiments were used to investigate catalytic activity for the aged parts. The relative locations for samples harvested for each of these analyses are shown in Figure 3. Further description of methods for postmortem analysis is included in the Results section of this paper.

\section{RESULTS}

\section{Thermal and Metal Exposure}

Following every 10 hours of catalyst aging, the DPF was removed from the exhaust system and weighed to determine total ash loading. The weighing took place following 30 minutes of operation with temperatures around $700^{\circ} \mathrm{C}$ (Mode $3)$. This ensured that minimal soot was present on the filter at the time of weighing. The filter was above $200^{\circ} \mathrm{C}$ at the time of weighing to prevent water adsorption. Table 3 shows the total amount of ash collected by the end of the 100 hours of simulated aging. The system aged with ULSD collected 28 grams of ash, which would primarily come from the engine's lubricant. As expected, each of the systems aged with B20 doped with metals collected higher levels of ash. It is expected that a portion of this ash on the B20 aged filters would also come from the lubricant oil with the rest coming from the metals doped into the fuel. The system aged with B20 containing $14 \mathrm{ppm}$ of $\mathrm{Ca}$ collected the most ash, at 82 grams. The DPF was the final component in the exhaust system; thus, the DOCs and SCRs ahead of the filter would have been exposed to these levels of ash at a minimum. Table $\underline{3}$ also shows thermal exposure data for each of the four systems. This table shows the time where the temperature is greater than $600^{\circ} \mathrm{C}$, generally considered to be DPF regeneration conditions, and the average temperature measured at the inlet to the SCR catalyst. As can be seen from this data, the thermal aging is very similar for each of the four systems. Thus, the primary difference between these systems is the amount and type of metal ash to which they were exposed.

Table 3. Thermal and Ash Exposure

\begin{tabular}{cccc}
\hline & $\begin{array}{c}\mathrm{SCR}>600^{\circ} \mathrm{C} \\
\text { (hrs) }\end{array}$ & $\begin{array}{c}\text { Average SCR } \\
\text { temp }\left({ }^{\circ} \mathrm{C} \text { ) }\right.\end{array}$ & $\begin{array}{c}\text { Ash Exposure } \\
\text { (grams) }\end{array}$ \\
\hline ULSD & 45.8 & 486 & 28 \\
$\mathrm{B20}+\mathrm{Na}$ & 43.9 & 488 & 66 \\
$\mathrm{~B} 20+\mathrm{Ca}$ & 44.8 & 493 & 82 \\
$\mathrm{~B} 20+\mathrm{K}$ & 45.1 & 484 & 59 \\
\hline
\end{tabular}

\section{Vehicle Emissions}

Following the DPF weighing procedure, the exhaust system was reassembled and installed onto a Ford F250 pickup truck for emissions testing. This occurred at 10-hour intervals throughout the accelerated aging and was always conducted utilizing ULSD fuel without biodiesel or doped metals. The first emissions test was conducted after 1 hour of aging to allow for some catalyst de-greening. Figure 4 shows the NOx emissions from the vehicle, measured in grams/mile, throughout the accelerated aging process. The final test 
Table 4. Bench Flow Reactor Conditions

\begin{tabular}{ccc}
\hline & $\begin{array}{c}\text { NOx Conversion } \\
\text { (Standard Reaction) }\end{array}$ & $\mathrm{NH}_{3}$ Oxidation \\
\hline $\mathrm{NH}_{3}(\mathrm{ppm})$ & 350 & 350 \\
$\mathrm{NO}(\mathrm{ppm})$ & 350 & 0 \\
$\mathrm{NO}_{2}(\mathrm{ppm})$ & 0 & 0 \\
$\mathrm{O}_{2}(\%)$ & 14 & 14 \\
$\mathrm{H}_{2} \mathrm{O}(\%)$ & 5 & 5 \\
$\mathrm{CO}_{2}(\%)$ & 5 & 5 \\
$\mathrm{Balance}$ & $\mathrm{N}_{2}$ & $\mathrm{~N}_{2}$ \\
$\mathrm{SV}\left(\mathrm{hr}^{-1}\right)$ & 30,000 & 30,000 \\
Temp $\left({ }^{\circ} \mathrm{C}\right)$ & $125-650$ & $125-650$ \\
\hline
\end{tabular}

conducted at 100 hours represents 150,000 miles of thermal aging and metal exposure. As illustrated in the figure, the NOx emission certification level for this vehicle is $0.2 \mathrm{~g} / \mathrm{mile}$. At the end of the 100-hour test, all four of the exhaust systems met the NOx emission standard and were within 0.03 $\mathrm{g} /$ mile of each other. Only a single FTP emissions test was run at each 10-hour interval throughout the aging process, therefore we cannot determine the test-to-test variability. Based on the absence of replicate data and the nearly identical result in the final emission test, it is difficult to draw any conclusions about catalyst deactivation as a result of metal exposure. Although it may be within the measurement uncertainty, the system aged with B20 containing Na failed the $0.2 \mathrm{~g} / \mathrm{mile}$ NOx emission standard at 60 hours of aging and the system aged with B20 containing $\mathrm{K}$ failed the standard at 80 hours and again at 90 hours. Figure 5 shows similar results for $\mathrm{HC}$ emissions where $0.2 \mathrm{~g} / \mathrm{mile}$ is the emission certification level. All four systems consistently pass the $\mathrm{HC}$ emission standard by a wide margin, and there are no apparent trends in the data throughout the 100 hours of aging to indicate deactivation of the DOC.

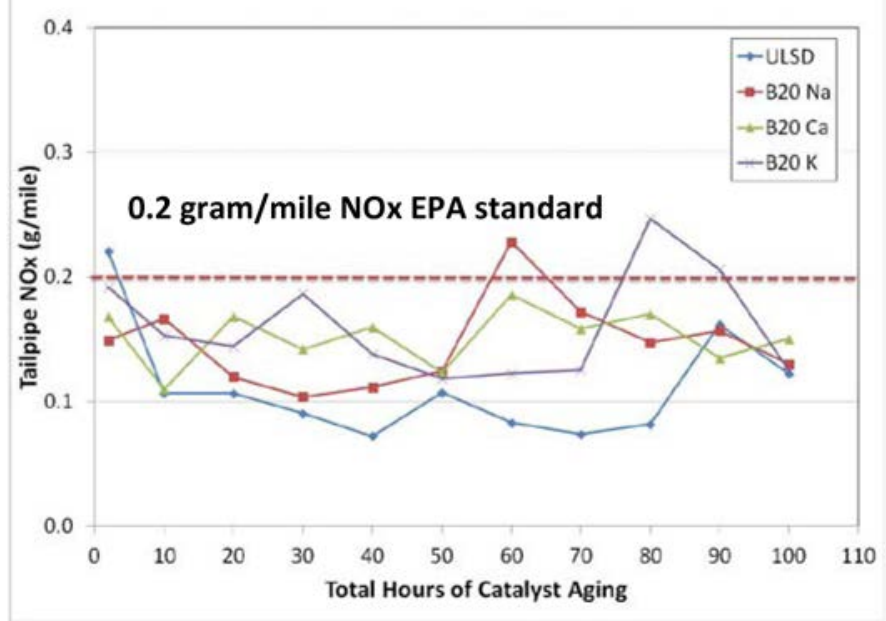

Figure 4. NOx emissions test results

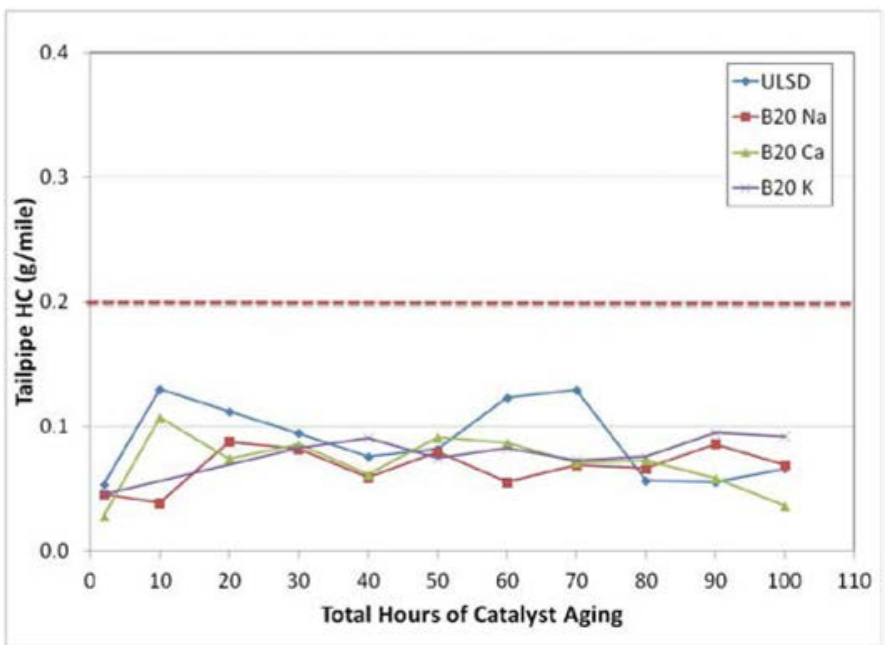

Figure 5. HC emissions test results

\section{SCR Postmortem Analysis}

Vehicle emissions tests give a measure of how the entire aftertreatment system is performing throughout the catalyst aging process. However, bench flow reactor experiments allow for more detailed characterization of catalyst performance, which could reveal signs of catalyst deactivation not seen in full system testing. For each of the aged SCR catalysts, 1 inch diameter by 1 inch long cores were harvested from each of the bricks, as shown in Figure 3 . Because there are two bricks in each system, this allowed for analysis of the first inch and the seventh inch (first inch of the second brick) of the full SCR catalyst length. The conditions for the $\mathrm{NOx}$ conversion and $\mathrm{NH}_{3}$ oxidation experiments are given in Table 4.

Figure 6 shows the NOx conversion performance over the first inch of the SCR catalyst for each of the four aged systems. This figure shows conversion performance for a range of temperatures from $125^{\circ} \mathrm{C}$ to $650^{\circ} \mathrm{C}$. The samples harvested from the catalyst aged with ULSD containing no metals and B20 containing Ca have nearly the same performance. Both of these aged samples achieve better than $90 \%$ NOx conversion between roughly $200^{\circ} \mathrm{C}$ and $400^{\circ} \mathrm{C}$. 
The first inch of the SCR catalysts aged with B20 containing $\mathrm{Na}$, and $\mathrm{B} 20$ containing $\mathrm{K}$, clearly have reduced performance over the majority of the tested temperature range. At $200^{\circ} \mathrm{C}$, the $\mathrm{Na}$ and $\mathrm{K}$ exposed catalysts only achieve about $70 \% \mathrm{NOx}$ conversion. The $\mathrm{K}$ exposed catalyst never achieved greater than $90 \%$ conversion throughout the temperature range.

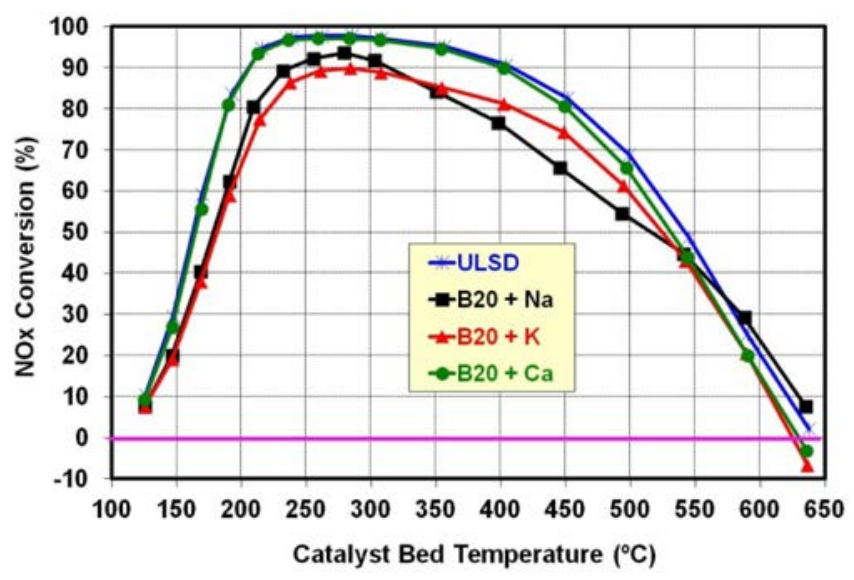

Figure 6. Standard SCR reaction for first inch of aged SCR catalysts

Figure 7 shows the NOx conversion achieved over the seventh inch (first inch of the second brick) of the aged SCR catalysts. Because the exhaust system has two 6 inch bricks mounted in series, this would represent the midpoint of the full SCR system. In this case all four of the systems performed identically at temperatures between roughly $125^{\circ} \mathrm{C}$ and $500^{\circ} \mathrm{C}$. The samples exposed to $\mathrm{Na}$ and $\mathrm{K}$ did show decreased performance above $500^{\circ} \mathrm{C}$, but this is outside of the normal operating range for these catalysts.

To illustrate the relevant operating range for this system in an F250 pickup, the inlet temperature of the SCR catalyst was measured during FTP and US06 drive cycles. Data from these driving events showed that the SCR catalyst primarily operates between $200^{\circ} \mathrm{C}$ and $300^{\circ} \mathrm{C}$ during an FTP emissions test and reaches peak temperatures of $385^{\circ} \mathrm{C}$ during the US06 cycle. However, the most challenging period of operation is the first two minutes of a cold start FTP where the catalyst operates below $200^{\circ} \mathrm{C}$, thus highlighting the importance of the lost performance at low temperatures for the $\mathrm{Na}$ and $\mathrm{K}$ aged samples.

Figure 8 shows the $\mathrm{NH}_{3}$ oxidation activity over the first inch of the SCR catalyst for each of the four aged systems. As was the case for NOx conversion performance, the systems aged with ULSD and B20 containing $\mathrm{Ca}$ are similar. The samples exposed to $\mathrm{Na}$ and $\mathrm{K}$ show very different results, with $\mathrm{Na}$ exposure causing $\mathrm{NH}_{3}$ oxidation to occur at lower temperatures and $\mathrm{K}$ exposure causing $\mathrm{NH}_{3}$ oxidation at higher temperatures. These changes in temperature for the onset of $\mathrm{NH}_{3}$ oxidation represent two different stages of catalyst degradation and has been demonstrated and described in previous work by Cavataio and coworkers [7]. The state of the $\mathrm{Cu}$ within the $\mathrm{Cu} /$ zeolite SCR catalyst has a direct impact on $\mathrm{NH}_{3}$ oxidation and the observed changes in $\mathrm{NH}_{3}$ oxidation are likely a result of $\mathrm{Cu}$ becoming freed-up from the zeolite structure.

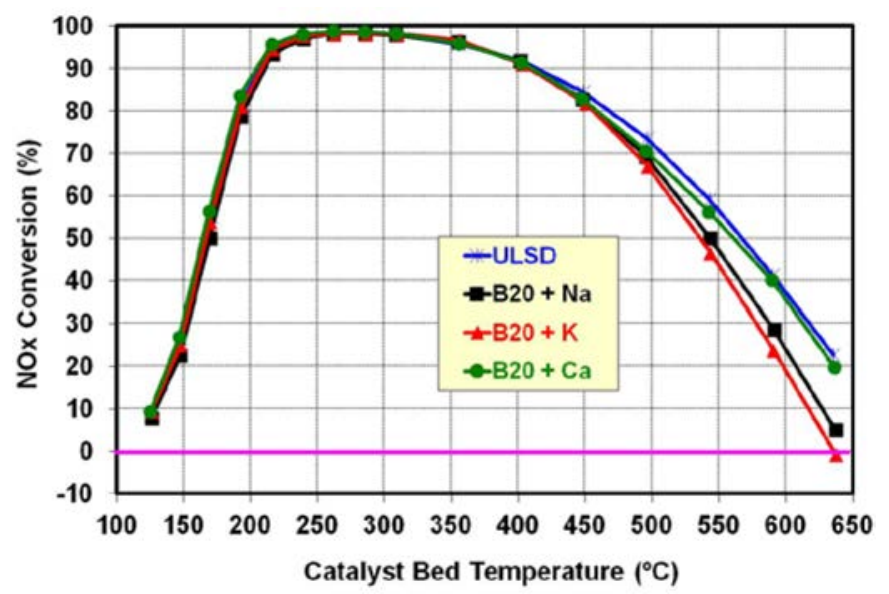

Figure 7. Standard SCR reaction for seventh inch of aged SCR catalysts

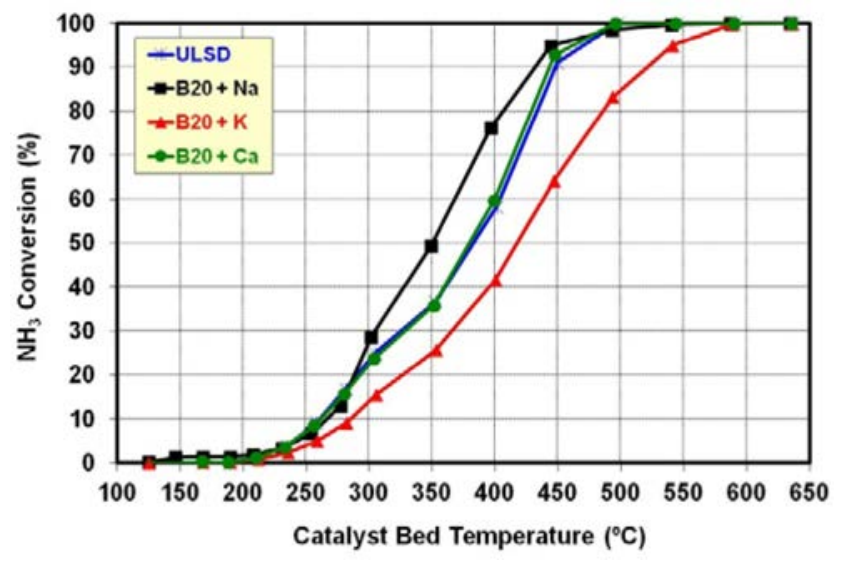

Figure 8. $\mathrm{NH}_{3}$ oxidation over first inch of aged $\mathrm{SCR}$ catalysts

Figure 9 shows the $\mathrm{NH}_{3}$ oxidation over the seventh inch of the aged SCR catalysts. In this case the performance is much more similar for each sample, however the samples exposed to $\mathrm{Na}$ and $\mathrm{K}$ have slightly higher $\mathrm{NH}_{3}$ oxidation. At $450^{\circ} \mathrm{C}$ $\mathrm{NH}_{3}$ oxidation is roughly $10 \%$ higher for the $\mathrm{Na}$ and $\mathrm{K}$ exposed samples than for the systems aged with ULSD and B20 containing Ca.

Using the bench flow reactor, experiments were also conducted to determine the $\mathrm{NH}_{3}$ storage capacity for each of the aged SCR samples. For this experiment the catalyst sample was maintained at $200^{\circ} \mathrm{C}$ for 3,600 seconds with 350 ppm of $\mathrm{NH}_{3}$ and $0 \mathrm{ppm}$ of NOx in the exhaust stream. This allowed the catalyst sample to adsorb $\mathrm{NH}_{3}$. By measuring the 
$\mathrm{NH}_{3}$ downstream of the SCR catalyst it is possible to determine how much $\mathrm{NH}_{3}$ the catalyst is able to store. This experiment is illustrated in Figure 10, which shows the $\mathrm{NH}_{3}$ profiles measured both upstream and downstream of the catalyst. The difference between the two profiles is used to calculate the total $\mathrm{NH}_{3}$ storage capacity. This total storage capacity is further divided into a strongly held portion and a weakly held portion. The strongly held portion represents chemical adsorption of the $\mathrm{NH}_{3}$ to the acid sites within the zeolite, whereas the weakly held portion represents physical adsorption or condensation of $\mathrm{NH}_{3}$. The differentiation between the two types of storage is marked by the onset of $\mathrm{NH}_{3}$ breakthrough measured downstream of the catalyst.

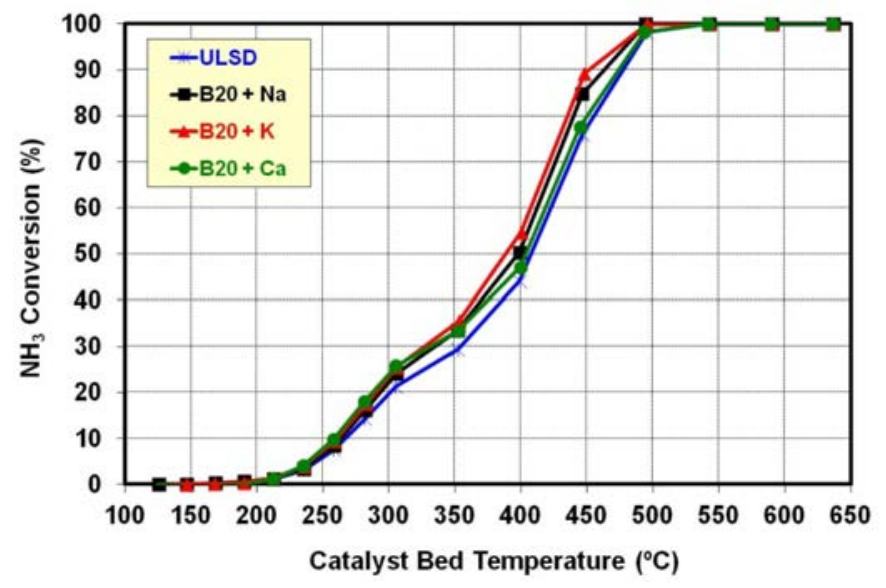

Figure 9. $\mathrm{NH}_{3}$ oxidation over seventh inch of aged $\mathrm{SCR}$ catalysts

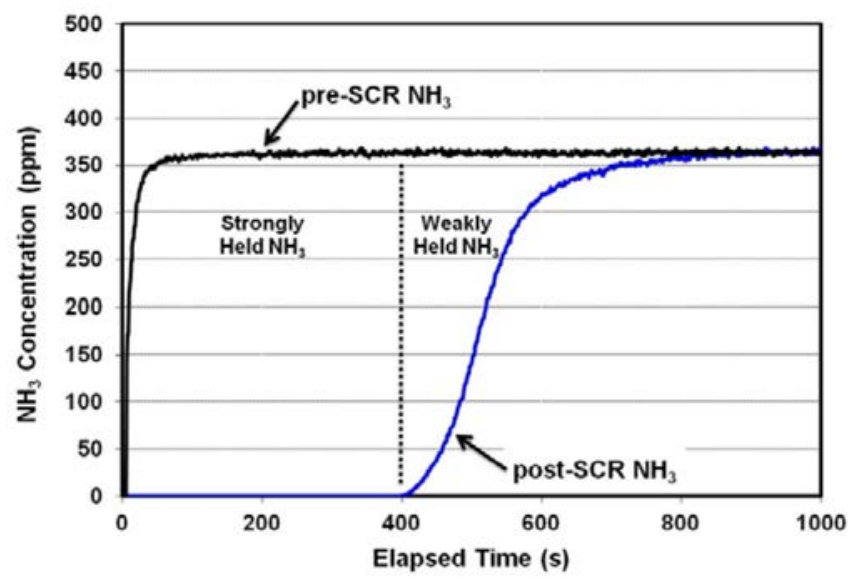

Figure 10. Example of $\mathrm{NH}_{3}$ adsorption experiment

Figure 11 shows the strongly held $\mathrm{NH}_{3}$ as a percentage of the total adsorption capacity for the first inch of the aged SCR catalysts. The adsorption experiment was run at three separate temperatures; $200^{\circ} \mathrm{C}, 250^{\circ} \mathrm{C}$ and $300^{\circ} \mathrm{C}$. In all three cases, the samples exposed to $\mathrm{K}$ and $\mathrm{Na}$ clearly have diminished capacity for strongly held $\mathrm{NH}_{3}$ storage. Figure 12 shows the strongly held $\mathrm{NH}_{3}$ as a percentage of total capacity for the seventh inch of the aged SCR catalysts. In this case all of the systems exposed to fuel metals have slightly lower capacity for strongly held $\mathrm{NH}_{3}$, however the impact is much less than what is seen in the first inch.

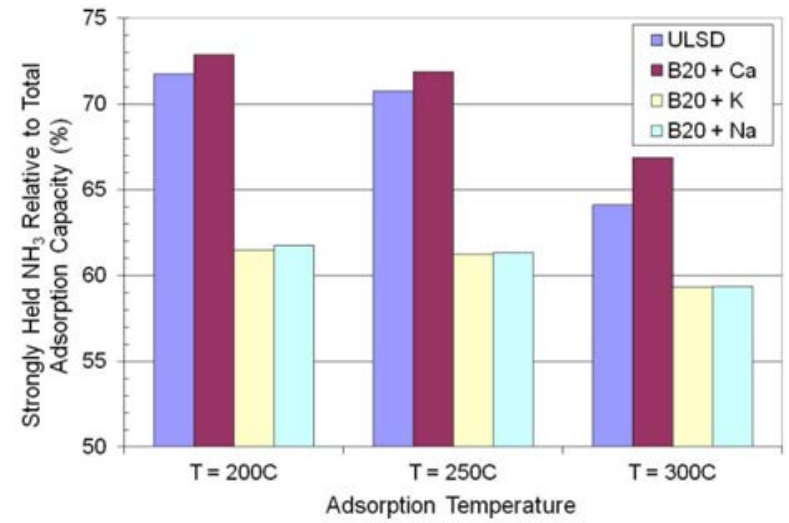

Figure 11. $\mathrm{NH}_{3}$ storage in first inch of the aged $\mathrm{SCR}$ catalysts

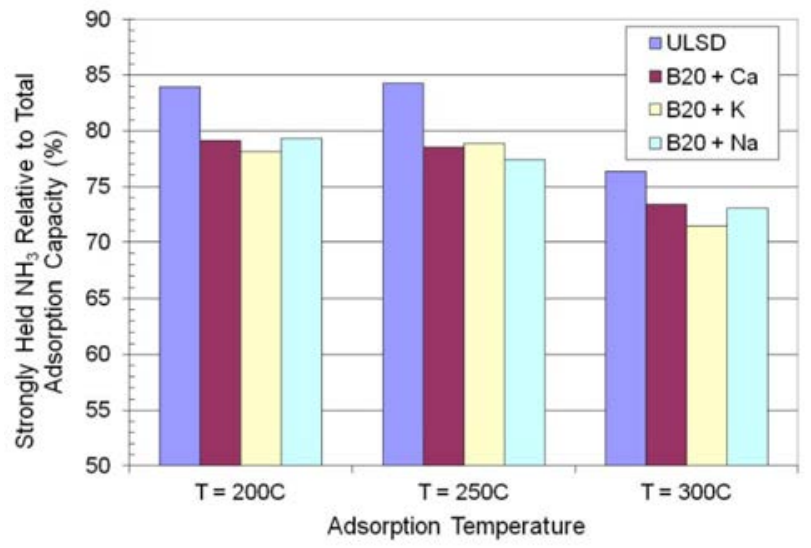

Figure 12. $\mathrm{NH}_{3}$ storage in seventh inch of the aged SCR catalysts

$\underline{\text { Figures } 13}, \underline{14}, \underline{15}, \underline{16}$ show EPMA micrographs for a quarter channel cross section of each of the aged SCR catalysts. The images highlight relative concentrations and distributions of $\mathrm{Ca}, \mathrm{Na}, \mathrm{K}$, and $\mathrm{P}$ in each of the samples. The color legend to the right of each image represents the spectrum of relative concentration for the elements, with red being the highest and dark blue representing background levels. Phosphorus was selected because it is a common additive in lubricating oils. As shown in Figure 3, these samples were taken from the front SCR, approximately one inch into the brick. These cross section images in Figures 13, 14, 15, 16 show the lower left hand corner of a single channel of the flow through the SCR catalyst, including both the washcoat and substrate. The substrate is in the lower left corner of each of the four images and shows visible porosity. The washcoat fills the corner of the substrate channel with the surface exposed to the exhaust flow located in the upper right hand corner. The exhaust flow direction is perpendicular to the plane of the image. Naturally 
occurring cracks divide the washcoat into sections which we designate as "corner" and "side" for the purpose of discussion. This is illustrated in Figure 13. In each of the four aged samples there is a thin layer of $\mathrm{P}$ deposited directly on top of the washcoat. In the case of the sample aged with $\mathrm{Ca}$, a thin, highly concentrated layer of $\mathrm{Ca}$ is deposited directly on top of the washcoat as well. There is no evidence of either the $\mathrm{P}$ or $\mathrm{Ca}$ penetrating into the washcoat. In the case of the $\mathrm{Na}$ exposed sample, the EPMA image shows an elevated signal for $\mathrm{Na}$ in the washcoat of the catalyst. A similar result is seen for the K-exposed sample with a high concentration of $\mathrm{K}$ in the washcoat. The alkali elements have diffused into the porous washcoat to the substrate surface rather than being isolated to the washcoat external surface like the $\mathrm{Ca}$ and $\mathrm{P}$. Also of note is that the side portion of the washcoat tends to show higher concentrations for the $\mathrm{Na}$ and $\mathrm{K}$ than the corner portions.

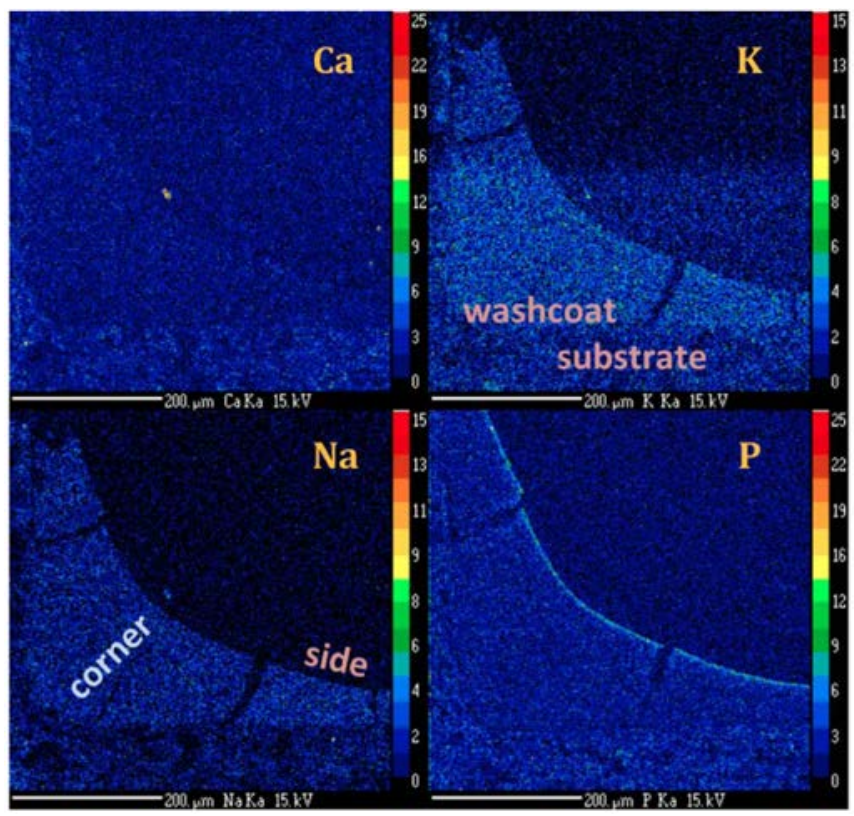

Figure 13. EPMA of first inch of ULSD aged SCR

Previous studies have employed similar accelerated techniques to probe the question of $\mathrm{Na}$ and $\mathrm{K}$ impact on SCR catalysis [7]. In particular, Brookshear et al. [14] investigated both chemical characterization with EPMA and performance impact with the key differences being the use of an older generation zeolite framework (Beta versus Chabazite) and exposure to much higher levels of $\mathrm{Na}$ (to mimic heavy duty exposure of 435,000 miles). Similar results were observed in the EPMA data, as $\mathrm{Na}$ was observed throughout the washcoat with higher concentrations in the side position. The performance deactivation was more significant in this investigation, but this is to be expected since the zeolite is more susceptible to thermal aging and the total $\mathrm{Na}$ exposure was nearly 3 times higher. The similarities in these findings suggest that the impact of $\mathrm{Na}$ is similar across all commercially relevant $\mathrm{Cu}$-exchanged zeolite. Extrapolation to Fe-zeolites cannot be made at this time. The proposed mechanism of substitution of the exchanged metal with $\mathrm{Na}$ or $\mathrm{K}$ is expected to still be relevant; however, the relative exchange strength would need to be probed in a similar manner as was done here.

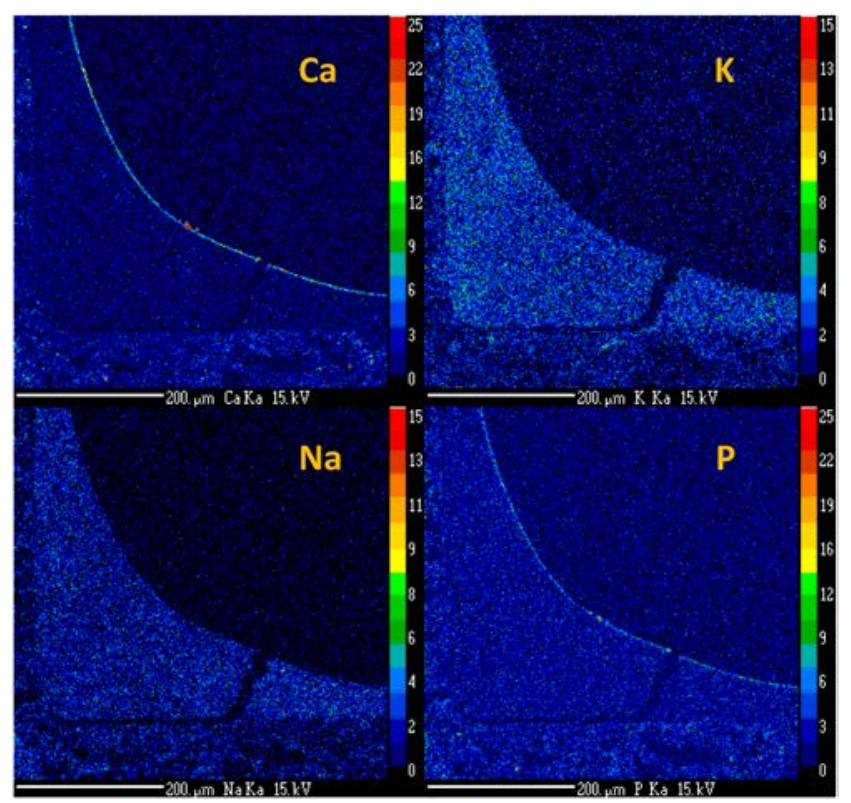

Figure 14. EPMA of first inch of Ca aged SCR

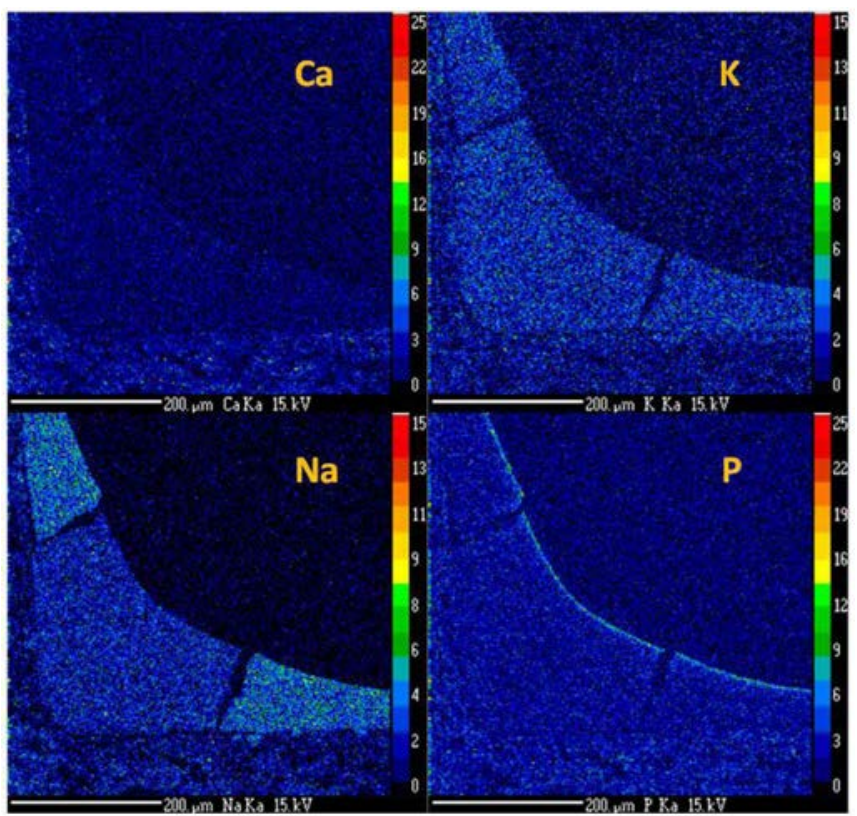

Figure 15. EPMA of first inch of Na aged SCR 


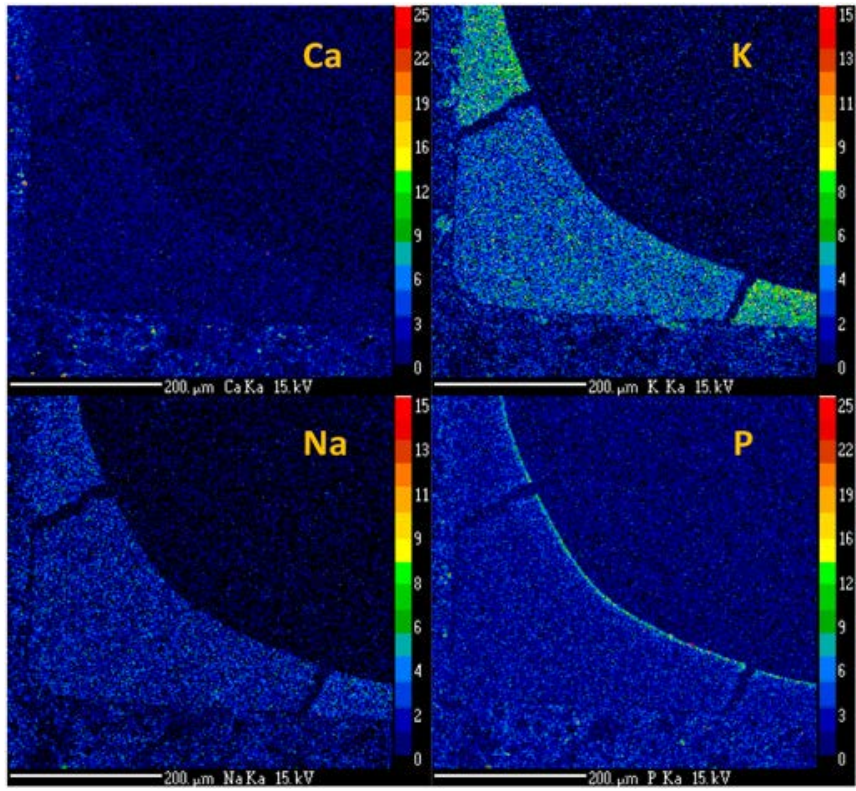

Figure 16. EPMA of first inch of K aged SCR

\section{DOC Postmortem Analysis}

For each of the aged DOC catalysts, 1 inch diameter by 1 inch long cores were harvested from the first brick and the second brick, as shown in Figure 3. Front and rear samples of the first brick and a front sample of the rear brick were analyzed in a bench flow reactor for CO light-off, HC lightoff, and $\mathrm{NO}$ oxidation, and for HC slip during simulated DPF regenerations. $\mathrm{CO}, \mathrm{HC}$, and $\mathrm{NO}$ oxidation experiments were carried out in a pulsator laboratory flow reactor where the combustion of iso-octane served to generate HC, NOx and CO levels. Table 5 shows the conditions for these DOC evaluation experiments. The gas temperature measured at the inlet of the DOC sample was ramped from $100^{\circ} \mathrm{C}$ to $650^{\circ} \mathrm{C}$ at a $10^{\circ} \mathrm{C} / \mathrm{min}$ ramp rate. $\mathrm{CO}$ and $\mathrm{HC}$ profiles were used to determine the temperature required for $50 \%$ (T50), $80 \%$ (T80), and $90 \%$ (T90) conversion. The nitrogen dioxide $\left(\mathrm{NO}_{2}\right)$ formation test consisted of determining the peak percentage of $\mathrm{NO}_{2}$ relative to total $\mathrm{NOx}$ and the corresponding temperature.

$\underline{\text { Figures } 17}$ and $\underline{18}$ show the results for the $\mathrm{HC}$ and $\mathrm{CO}$ lightoff for each of the aged DOC samples. Light-off temperatures are shown for $50 \%$ (T50), 80\% (T80), and 90\% (T90) conversion. The T50 and T80 HC light-off temperatures were similar for all four of the aged DOCs. However, the T90 HC light-off temperatures were significantly higher for the $\mathrm{K}$ and $\mathrm{Na}$ exposed parts. In the case of the CO light-off, the T50 temperatures were also similar for all four aged systems. However, the T90 light-off temperature was higher for the $\mathrm{Ca}, \mathrm{K}$, and $\mathrm{Na}$ exposed parts. This effect was mostly observed further down the length of the catalyst and was most prominent for the DOCs exposed to Na.
Table 5. Flow Reactor Conditions for $\mathrm{HC}, \mathrm{CO}$ and NO Oxidation Experiments

\begin{tabular}{|c|c|}
\hline Feed Gas Composition & Evaluation Conditions \\
\hline $\begin{array}{l}\text { HC: Iso-Octane Clear } \\
\text { (ppmC1) }\end{array}$ & $1,500-1,800$ \\
\hline $\mathrm{CO}$ (ppm) & 2,500 \\
\hline NOx (ppm) & $350-450$ \\
\hline $\mathrm{O}_{2}(\%)$ & 10 \\
\hline $\mathrm{H}_{2} \mathrm{O}(\%)$ & $>5$ \\
\hline $\mathrm{CO}_{2}(\%)$ & $>12$ \\
\hline Balance & $\mathrm{N}_{2}$ \\
\hline SV $\left(\mathrm{hr}^{-1}\right)$ & 50,000 \\
\hline
\end{tabular}

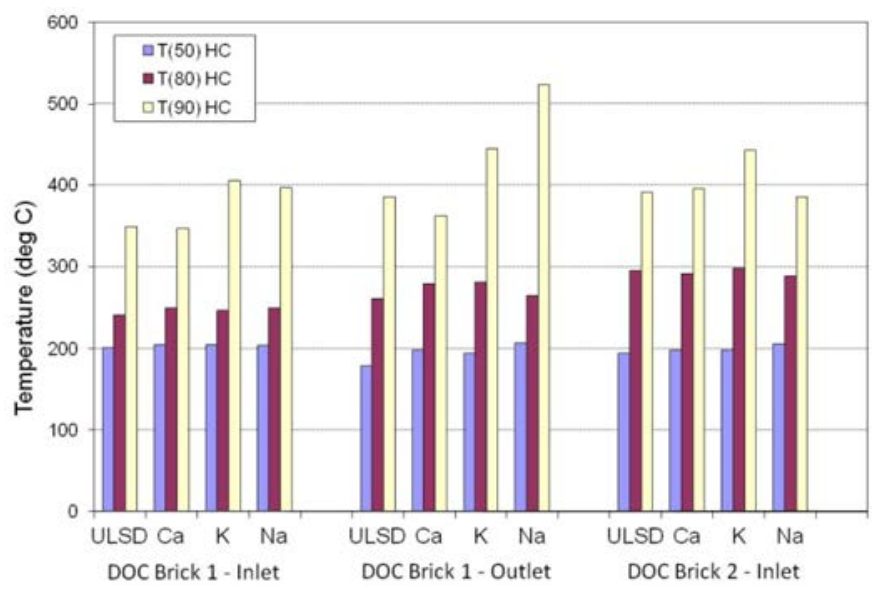

Figure 17. HC light-off temperatures

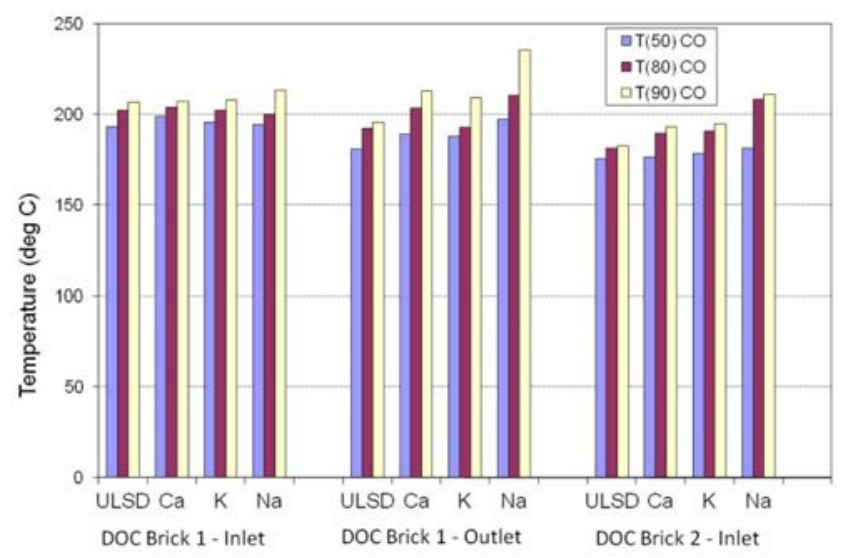

Figure 18. CO light-off temperatures

Figure 19 shows the peak $\mathrm{NO}_{2}: \mathrm{NOx}$ ratio and the corresponding temperature for each of the aged DOCs. The only significant finding is the small loss of NO oxidation function for the DOC exposed to $\mathrm{K}$. 


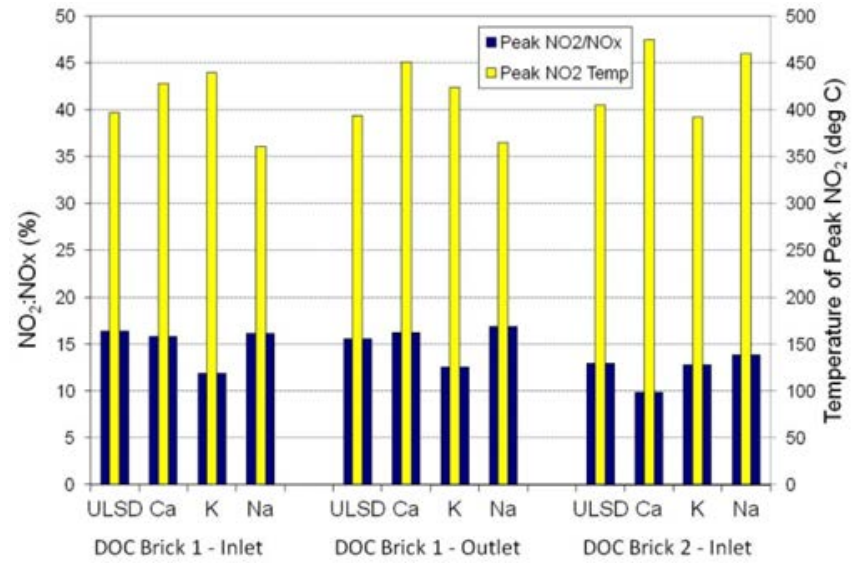

Figure 19. NO oxidation

Experiments to evaluate the DOC for HC slip during a DPF regeneration were carried out in a flow reactor designed for air-assisted diesel fuel injection upstream of a DOC sample. The inlet gas temperature was held constant at $300^{\circ} \mathrm{C}$ and a sufficient amount of diesel fuel was injected to generate an outlet temperature of $650^{\circ} \mathrm{C}$. The steady-state $\mathrm{HC}$ and nonmethane hydrocarbon breakthrough was measured for each of the aged DOC samples. Figure 20 shows the results for the $\mathrm{HC}$ slip during a simulated DPF regeneration. This plot shows the HC slip for the three different DOC cores. In every position, the samples exposed to $\mathrm{K}$ showed higher levels of HC slip compared to the samples aged with ULSD and B20 containing $\mathrm{Ca}$. The samples exposed to $\mathrm{Na}$ showed higher levels of HC slip further down the length of the catalyst.

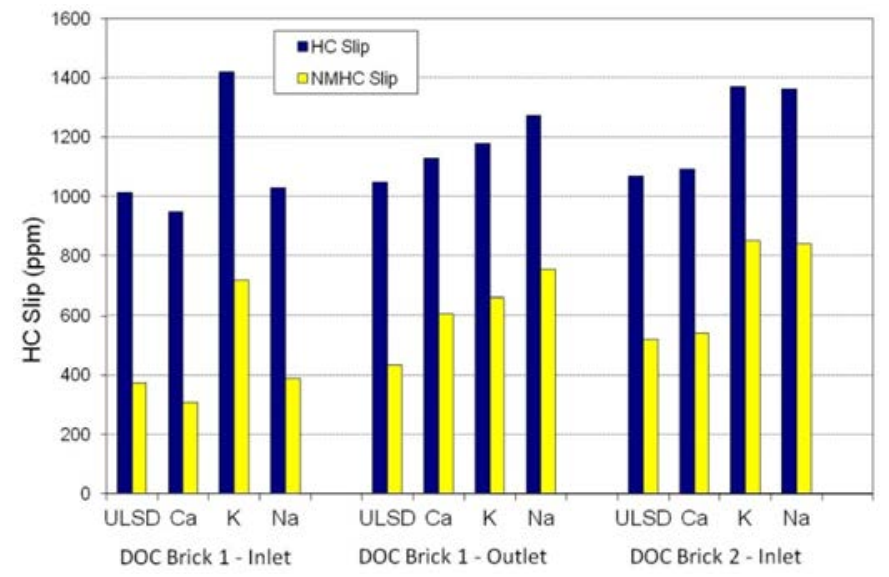

Figure 20. HC slip during regeneration

Figures $21, \underline{22}, \underline{23}, \underline{24}$ show EPMA micrographs obtained for each of the aged DOCs. The substrate and catalyst washcoat positions are the same as described for Figures 13, 14, 15, $\underline{16}$, i.e., from the front DOC approximately one inch into the brick, as shown in Figure 3. These images show the relative concentration and distribution of $\mathrm{Na}, \mathrm{K}, \mathrm{Ca}$, and $\mathrm{P}$ in each of the samples. Unlike the SCR samples the channels of the DOC contain two separate layers. The corners appear to contain an inert filler and a thin layer of active catalyst is washcoated onto the substrate; this last layer will be referred to as the primary washcoat. In each case a thin layer of P can be seen not only at the surface of the DOC washcoat, but it also has penetrated throughout the thin primary washcoat layer. In the case of the $\mathrm{Ca}$ exposed sample, a layer of $\mathrm{Ca}$ can also be seen on the surface of the washcoat. In the case of the $\mathrm{Na}$ and $\mathrm{K}$ exposed samples, large amounts of the alkali metals have diffused throughout the primary washcoat and penetrated the underlying filler. This indicates a high level of interaction between these metals and the catalyst materials, which are even reactive enough to penetrate the underlying nonporous material including the cordierite.

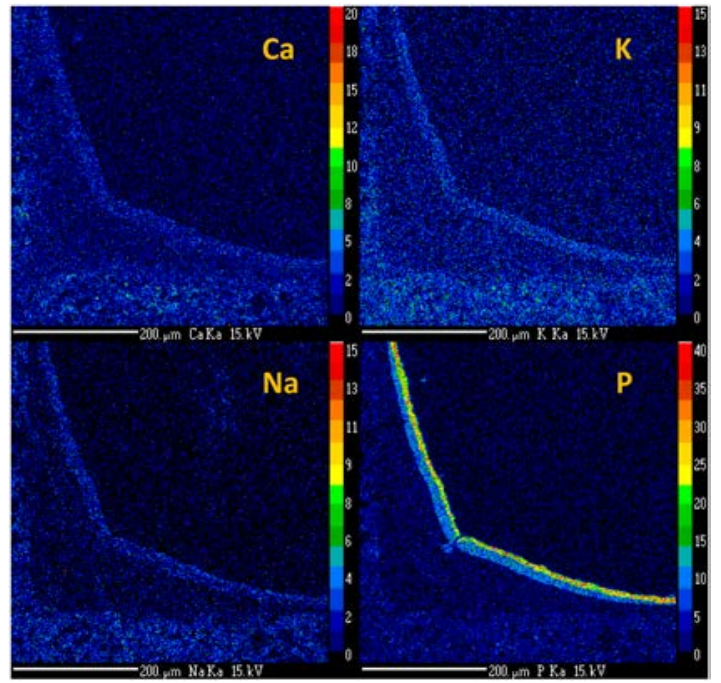

Figure 21. EPMA of first inch of ULSD aged DOC

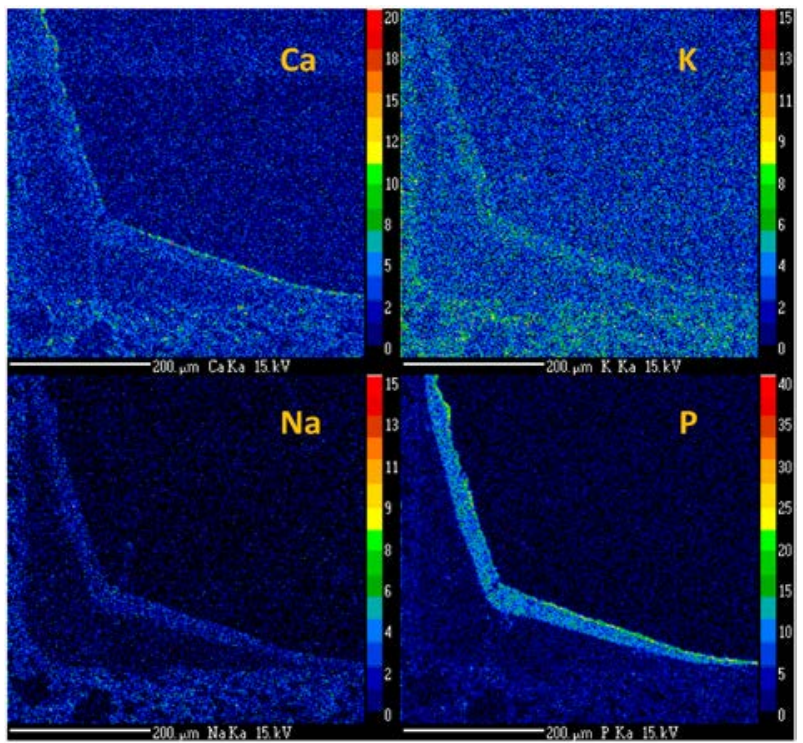

Figure 22. EPMA of first inch of Ca aged DOC 


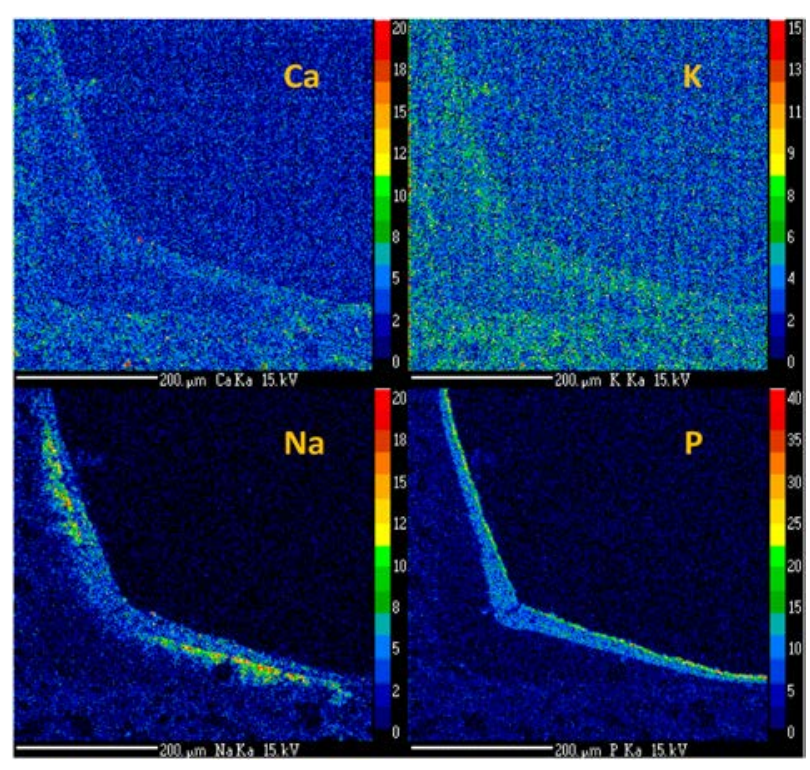

Figure 23. EPMA of first inch of Na aged DOC

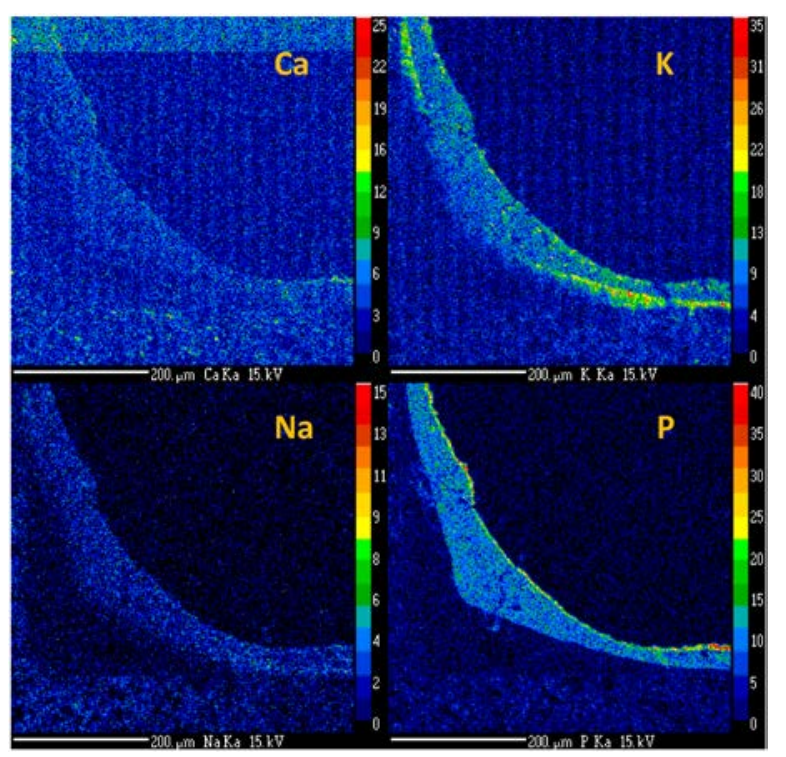

Figure 24. EPMA of first inch of K aged DOC

\section{DPF Postmortem Analysis}

Measurements of fracture strength, elastic modulus, and coefficient of thermal expansion (CTE) were taken for each of the four aged DPFs as well as a fresh DPF. A critical parameter for estimating DPF durability is the thermal shock resistance (RS):

$$
R_{s}=\frac{K \sigma_{f}(1-v)}{\alpha E}
$$

where $\mathrm{K}$ is the thermal conductivity, $\sigma_{\mathrm{f}}$ is the tensile fracture strength, $v$ is the Poisson's ratio, $\alpha$ is the CTE, and E is the elastic modulus. It is desirable to maximize $R_{S}$. Failure is likely to occur during regeneration when the thermal gradients are largest, so any increase in the elastic modulus and CTE or decrease in the fracture strength and thermal conductivity will be detrimental to the DPF durability.

For measurement of material strength, approximately 70 tiles, each $30 \times 30 \mathrm{~mm}$ square, were extracted down the length of the DPF. One-half of the tiles were taken from the radial center of the DPF while the other half were taken closer to the radial edge. Each individual tile was subject to a ring-onring biaxial flexure test as described in Reference [15]. This test measured the force and displacement at failure from which the elastic modulus and tensile fracture strength were estimated. This was done by modeling the same loading scenario and DPF strut structure using finite element analysis and then adjusting the elastic modulus in the model until it matched the load and displacement measured at the point of fracture after the subtraction of the compliance introduced by the testing equipment. Once the elastic modulus was determined, the fracture strength was calculated. The estimated elastic modulus and tensile fracture strength is shown in Figure 25 alongside the average specimen thickness for both the center and edge locations. This data is shown for each of the aged samples as well as for a fresh sample.

Both the elastic modulus and the fracture strength increase with the ULSD, B20+K, and B20+Na samples, but they decline slightly with the $\mathrm{B} 20+\mathrm{Ca}$ samples relative to the fresh sample. However, the specimen thickness also follows the same trend which resulted from difficulties in machining the $\mathrm{SiC}$ material. It cannot be ruled out that the different response in mechanical properties was largely caused by the change in specimen thickness and not from exposure as the thicker specimens will have higher contact stresses causing either the loading rings to crush the specimen or the specimen to flatten the rings thereby erroneously increasing the measured failure force. Nevertheless, because the estimated elastic modulus correlates with fracture strength in Figure 25, and these two properties are, respectively, in the denominator and numerator of Equation 1, the effect on the thermal shock resistance will be negligible. Moreover, resonant ultrasound measurements were conducted on samples from all the conditions and locations in Figure 25 but on specimens with identical dimensions and no statistically significant change in elastic modulus was observed, thereby suggesting that the changes measured in Figure 25 are related to specimen thickness and not engine testing.

Measurement of the CTE was conducted using a dual-rod dilatometer. The CTE specimens were 3 by 3 DPF channels square and one inch in length. A small spring load was applied along the axial direction of the specimen and the expansion with temperature was measured. Figure 26 shows the CTE for each of the aged samples as well as a fresh DPF. The CTE for all samples is approximately $4 \times 10^{-6} /{ }^{\circ} \mathrm{C}$ at $200^{\circ} \mathrm{C}$ and rises to approximately $5.5 \times 10^{-6} /{ }^{\circ} \mathrm{C}$ at $800^{\circ} \mathrm{C}$. There is no apparent difference in the CTE responses 
between any of the aged parts and the fresh sample. Some samples had broad peaks in the thermal expansion curve above $800^{\circ} \mathrm{C}$ which may be due to phase transformations in the ash that is present between the sample and the loading rod.

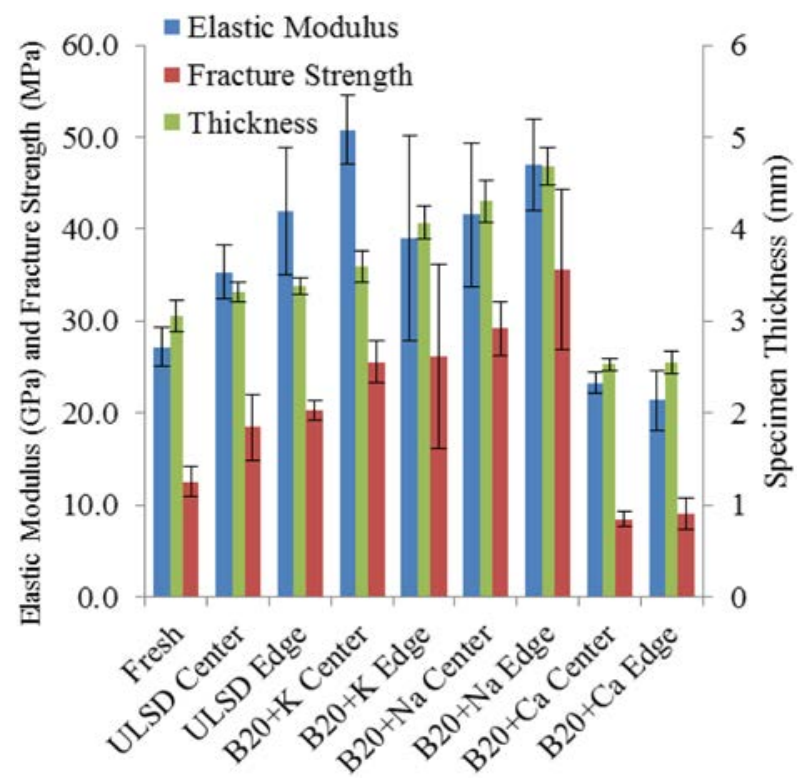

Figure 25. The estimated tensile fracture strength, estimated elastic modulus and thickness of the DPF samples

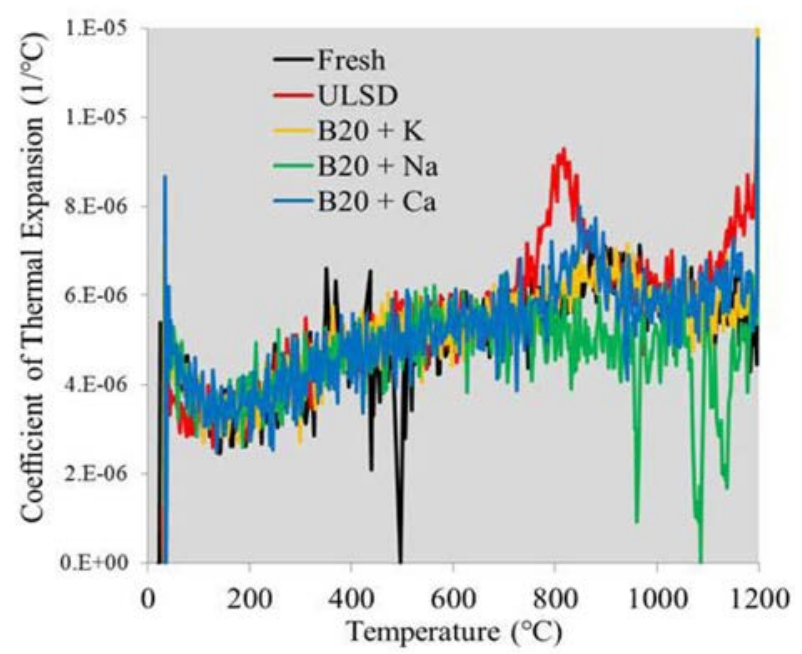

Figure 26. CTE versus temperature for the aged and fresh DPF samples

The aged and fresh samples were mounted in epoxy and the microstructure was observed both optically and with a scanning electron microscope; no evidence of cracking or corrosion was found. Energy-dispersive X-ray spectra were also collected from the $\mathrm{SiC}$ in each condition and no evidence of diffusion of metal species into the $\mathrm{SiC}$ structure or grain boundaries was detected. These observations coupled with the thermo-mechanical measurements show that there was no measureable degradation of the SiC DPF caused by exposure to the fuel metal impurities.

\section{SUMMARY / CONCLUSIONS}

An earlier study showed that alkali and alkaline earth metals could have a significant impact on the catalytic activity of a DOC and the thermo-mechanical durability of a DPF in a heavy-duty application [12]. The purpose of the work presented in this paper was to investigate the impact of these metal impurities in a light-duty application, with the additional concern that the SCR catalyst is located in front of the DPF where it will see more thermal and metal exposure.

Bench flow reactor experiments conducted on samples taken from each of the aged SCR catalysts showed that parts exposed to $\mathrm{Na}$ and $\mathrm{K}$ had reduced catalytic activity. However, this reduced performance was only seen in the first inch of the catalyst and was no longer observed further down the length of the catalyst. The cause of this deactivation is further explained by EPMA analysis of the SCR, which show that the $\mathrm{Na}$ and $\mathrm{K}$ have migrated into the catalyst washcoat, whereas $\mathrm{Ca}$ and lube oil derived Phosphorous remain on the washcoat surface. The overall magnitude of this SCR deactivation seen in the first inch of the catalyst is put into perspective by conducting FTP emissions tests of the full aftertreatment system. Emissions tests with a Ford F250 pickup showed that all of the systems continued to meet the $0.2 \mathrm{~g} / \mathrm{mile}$ NOx emission standard after the equivalent of 150,000 miles of accelerated aging. Bench flow reactor and EPMA studies of the aged DOCs showed similar signs of deactivation for parts exposed to $\mathrm{Na}$ and $\mathrm{K}$. However, the vehicle also continued to meet the $\mathrm{HC}$ emission standards with each of the aged systems. The vehicle emission testing and postmortem results taken together indicate that the alkali metals, $\mathrm{Na}$, and $\mathrm{K}$ are volatile at temperatures typically seen in diesel exhaust, which allows them to migrate into the catalyst washcoat leading to catalyst deactivation. However, after the simulated equivalent of 150,000 miles of exposure, there remains enough unaltered catalyst volume that impacts on tailpipe vehicle emissions are not observed. In addition the thermo-mechanical properties of the aged SiC DPFs were unchanged relative to each other and to a fresh DPF.

\section{REFERENCES}

1. Graboski, M.S. and McCormick, R.L., "Combustion of Fat and Vegetable Oil Derived Fuels in Diesel Engines," Progress in Energy and Combustion Science, 24 125-163, 1998.

2. Alleman, T.L., McCormick, R.L., "Results of the 2007 B100 Quality Survey," NREL/TP-540-42787, Golden, CO: National Renewable Energy Laboratory, March 2008.

3. Alleman, T.L., Fouts, L., and Chupka, G.M., "Quality Parameters and Chemical Analysis for Biodiesel Produced in the United States in 2011," Golden, CO: National Renewable Energy Laboratory, in preparation. 
4. Schwab, S., Bennett, J., Dell, S., Galante-Fox, J. et al., "Internal Injector Deposits in High-Pressure Common Rail Diesel Engines," SAE Int. J. Fuels Lubr. 3(2):865-878, 2010, doi:10.4271/2010-01-2242.

5. Quigley, R., Barbour, R., Fahey, E., Arters, D.C., Wetzel, W., Ray, J., "A Study of the Internal Diesel Injector Deposit Phenomenon," Proceedings of Fuels: conventional and future energy for automobiles, 8th International Colloquium,

Esslingen, 19-20 January 2011, www.lubrizol.com/9040Zer0/ IDIDQuigleyTAEEsslingen.pdf

6. Dou, D. and Balland, J., "Impact of Alkali Metals on the Performance and Mechanical Properties of NOx Adsorber Catalysts," SAE Technical Paper 2002-01-0734, 2002, doi: $\underline{10.4271 / 2002-01-0734 .}$.

7. Cavataio, G., Jen, H., Dobson, D., and Warner, J., "Laboratory Study to Determine Impact of $\mathrm{Na}$ and $\mathrm{K}$ Exposure on the Durability of DOC and SCR Catalyst Formulations," SAE Technical Paper 2009-01-2823, 2009, doi:10.4271/2009-01-2823.

8. Williams, A., McCormick, R., Hayes, R., Ireland, J. et al., "Effect of Biodiesel Blends on Diesel Particulate Filter Performance," SAE Technical Paper 2006-01-3280, 2006, doi:10.4271/2006-01-3280.

9. Williams, A., Pedersen, D., Ireland, J., McCormick, R. et al., "Effect of Biodiesel Blends on Urea Selective Catalytic Reduction Catalyst Performance with a Medium-Duty Engine," SAE Technical Paper 2008-01-2484, 2008, doi: 10.4271/2008-01-2484.

10. Tatur, M., Nanjundaswamy, H., Tomazic, D., Thornton, M. et al., "Biodiesel Effects on U.S. Light-Duty Tier 2 Engine and Emission Control Systems - Part 2," SAE Int. J. Fuels Lubr. 2(1):88-103, 2009, doi:10.4271/2009-01-0281.

11. Williams, A., Ratcliff, M., Pedersen, D., McCormick, R. et al., "Effect of Unburned Methyl Esters on the $\mathrm{NO}_{\mathrm{x}}$ Conversion of Fe-Zeolite SCR Catalyst," SAE Int. J. Fuels Lubr. 2(2):273-282, 2010, doi:10.4271/2009-01-2777.

12. Williams, A., McCormick, R., Luecke, J., Brezny, R. et al., "Impact of Biodiesel Impurities on the Performance and Durability of DOC, DPF and SCR Technologies," SAE Int. J. Fuels Lubr. 4(1):110-124, 2011, doi:10.4271/2011-01-1136.

13. Code of Federal Regulations: Protection of the Environment, Title 40 CFR Part 86, U.S. Environmental Protection Agency, http://www.epa.gov/lawsregs/ regulations/.

14. Brookshear D.W., Nguyen K., Toops T.J., Bunting B.G., Rohr W.F., Howe J., "Investigation of the effects of biodiesel-based $\mathrm{Na}$ on emissions control components", Catalysis Today 184 (2012) 205-218.].

15. Wereszczak, A., Fox, E., Lance, M., and Ferber, M., "Failure Stress and Apparent Elastic Modulus of Diesel Particulate Filter Ceramics," SAE Int. J. Mater. Manf. 5(2): 517-527, 2012, doi:10.4271/2012-01-1252.

\section{CONTACT INFORMATION}

Aaron Williams

National Renewable Energy Lab

15013 Denver West Parkway

Golden, CO 80401

(303) 275-3153

aaron.williams@nrel.gov

\section{ACKNOWLEDGMENTS}

Support from the National Biodiesel Board, the United Soybean Board, the U.S. Department of Energy, Office of Vehicle Technologies, Fuels Technologies Program and Propulsion Materials Programs is gratefully acknowledged. The authors would like to acknowledge the support of Roger Gault of the Truck and Engine Manufacturers Association and an industry technical steering committee comprised of engine and emission control experts for their technical input used in developing the accelerated durability test protocol. We would also like to acknowledge the contributions of Shirley Waters in the collection of the CTE data.

\section{DEFINITIONS/ABBREVIATIONS}

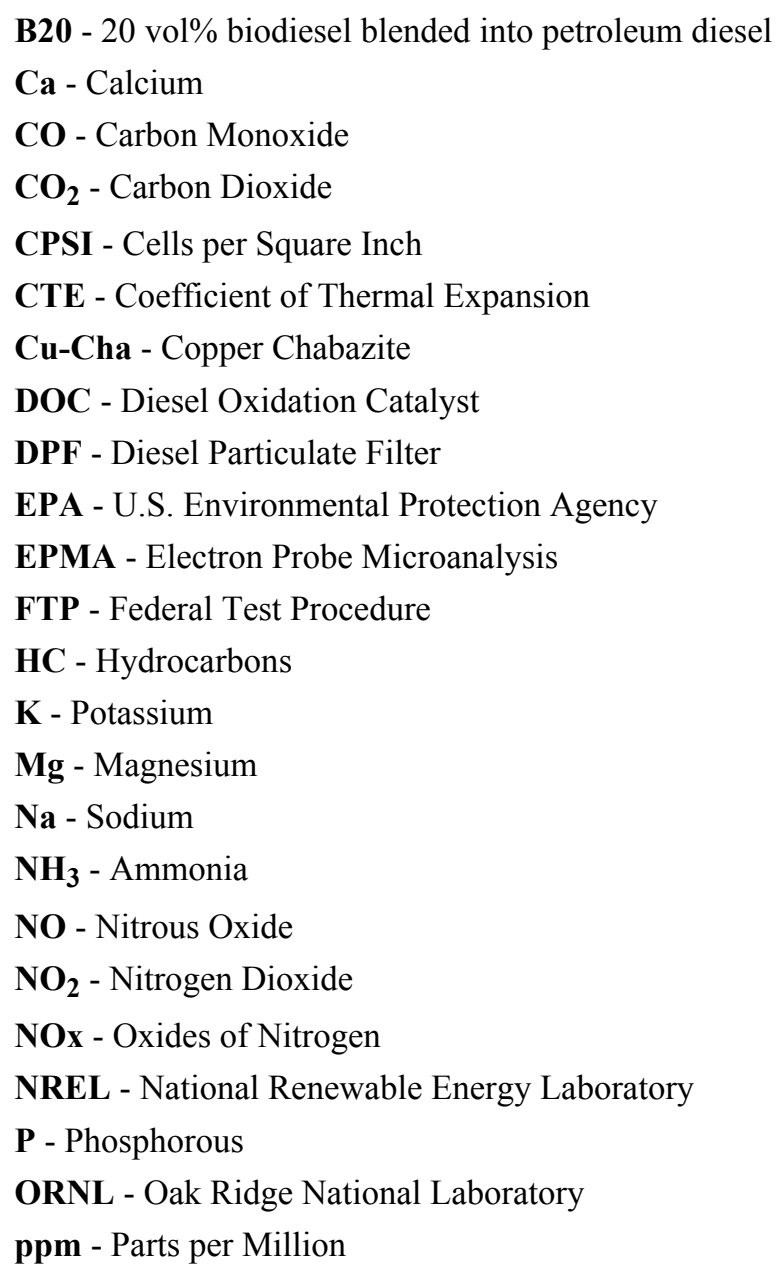


Rs - Thermal Shock Resistance Parameter

SCR - Selective Catalytic Reduction Catalyst

SV - Space Velocity

ULSD - Ultra Low Sulfur Diesel ( $<15 \mathrm{ppm}$ Sulfur)

The Engineering Meetings Board has approved this paper for publication. It has successfully completed SAE's peer review process under the supervision of the session organizer. This process requires a minimum of three (3) reviews by industry experts. ISSN 0148-7191
Positions and opinions advanced in this paper are those of the author(s) and not necessarily those of SAE. The author is solely responsible for the content of the paper.

SAE Customer Service:

Tel: 877-606-7323 (inside USA and Canada)

Tel: 724-776-4970 (outside USA)

Fax: 724-776-0790

Email: CustomerService@sae.org

SAE Web Address: http://www.sae.org

Printed in USA 